\title{
Los dos autores de La Florida
}

\author{
POR JOSÉ DURAND
}

Vislumbrar el misterio de la creación y composición de la Florida del Inca, equivale a entrar en la historia de una entrañable amistad: la del conquistador Gonzalo Silvestre y el Inca Garcilaso de la Vega. En el Proemio al letor el propio Garcilaso cuenta cómo de repetidas conversaciones con un amigo suyo, cuyo nombre oculta, nació el deseo de escribir esa obra. Silvestre, de edad mucho mayor que el Inca, había estado en la jornada de Hernando de Soto en la Florida y luego pasó al Perú, en donde alcanzó a defender el pendón real durante las guerras civiles de Gonzalo Pizarro y Francisco Hernández Girón, que por entonces alborotaron la tierra.

Silvestre podría representar hoy al típico conquistador que, vuelto a España sin haber logrado en Indias riquezas ni posesio-

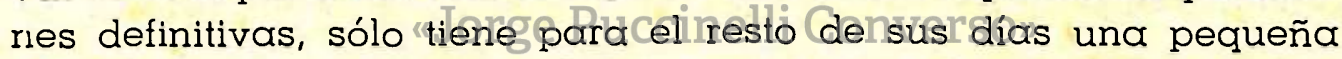
renta y un agobiante caudal de memoria -los grandes hechos que realizó o vio realizar, participando en ellos directa o indirectamente.

Como gran número de viejos conquistadores, primeros pobladores y otros ilustres indianos, como lo haría también el Inca Garcilaso, Silvestre solicitó rentas de la Corona. Y en el respectivo expediente de información de servicios, cuyo manuscrito se conserva en el Archivo de Indias, aparecen noticias que presentan a Silvestre como el perulero esforzado en la guerra e infortunado en bienes materiales. En enero de 1558, el testigo Francisco de Talavera -demos un ejemplo- declara que, en las guerras civiles del Perú, Silvestre "había gastado mucha suma de pesos de oro, en cantidad de más de ocho o diez mil ducados........ Este testigo conoció al dicho Gonzalo Silvestre, en la dicha Villa de la Plata e asiento de Potosí, mucha hacienda de heredades de pan 
y casas, negros e minas e que se decía........ que valía su hacienda más de diez mil pesos".

Ya desde el Perú, los azares de las guerras civiles, los pleitos entre los de Gonzalo y los del rey, le causaron grandes sinsabores. Cuando el virrey marqués de Cañete siguió la política de despedir pedigüeños y asentar el mundo colonial en perjuicio del mundo de los conquistadores, Gonzalo Silvestre sufrió las consecuencias. En 1556, el oidor Cuenca, por orden de Cañete, ordena en Lima información contra tres capitanes y otros que han hablado "palabras desacatadas y bulliciosas". Allí se ventila también la causa de Silvestre y no falta un pizarrista, un tal Iñigo López Carrillo, de Toledo, condenado a galeras por seguidor de Gonzalo, quien levanta contra él cargos graves en demasía:

Que también se acuerda este testigo haber topado al dicho Gonzalo Silvestre en la villa de la Plata cuando fue con el Mariscal [Alvarado] al castigo de los alzados; donde entendió este testigo que se halló cuando mataron a Pedro de Hinojosa e Alonso de Castro, su teniente; y cree este testigo que si el dicho Silvestre bajó acá abajo con el mariscal, fue recelándose el dicho mariscal no le castigase; y que al tiempo que el dicho mariscal hizo gente para el castigo de Francisco [Hernández] Girón, lo envió a llamar a la villa de la Plata para que sirviese a Su Majestad Jy sobreumandarléque/casentase en una compañía, $y$ el dicho querer entrar en otra, habló descatadamente contra el dicho mariscal y sobre ello le tuvo por matar, y entonces oyó este testigo decir al dicho mariscal que el dicho Silvestre no quiere escarmentar, ni asentar, déjamelo ahorcar y escarmentarán otros. Y así, a luego de muchas personas, lo dejó de hacer.

Las acusaciones del pizarrista López Carrillo, quizá exageradas al inculparlo, aunque inciertamente, de haber intervenido en la muerte de Hinojosa, entrañan un punto cierto: el del carácter bronco, irascible y desavenido, con el cual reaparece en todo ese proceso, y aun en testimonios muy tardíos, como veremos. QQuién dijera que ese capitán colérico iba a hacer eternas migas con el Inca Garcilaso, hasta hermanarse en la obra de la Florida!

Del mismo mal carácter quedan otras noticias en ese proceso, al aparecer contestes López Carrillo y otros dos declarantes, 
en torno a un arrebatado episodio: cuando Silvestre pretendió a viva fuerza poseer a la mujer del marino Antón de Rodas, mientras éste andaba navegando tranquilo y ausente de tales riesgos. López Carrillo atestigua.

.que en esta Ciudad de los Reyes fue cosa pública e notoria que Gonzalo Silvestre entró en la casa de Antón de Rodas, estando ausente destos reinos, y que había querido forzar a su mujer, sobre lo cual la Audiencia le tuvo preso en la cárcel real desta Corte, sobre lo cual se hizo proceso, al que se remite.

A su vez, Diego de Porras manifiesta:

que sabe que Gonzalo Silvestre posaba con el dicho Diego López de Zúñiga [uno de los tres capitanes después sentenciados], y que era grande amigo suyo, y se juntaba con los demás capitanes, y andaba con ellos juntos a fatigar a los oidores para que repartiesen la tierra, y que un día este testigo le fue a prender porque decían que había entrado en la casa de Antón de Rodas, estando él ausente, a forzar a su mujer, y que lo halló en la casa de Diego López de Zúñiga, donde lo prendió.

\section{Biblioteca de Letras}

Más pintorescaj resulta qún la lescenqen boca del capitán Diego Díaz :

Que un día la mujer de Antón de Rodas envió a llamar a este tesiigo y le dijo cómo un hombre de tal seña y de tal seña, que fue por el dicho Gonzalo Silvestre, había entrado un día en su casa estando su marido ausente, y era maestre y señor de un navío, y que la poseyó de un brazo para quererla abrazar y besar y que una prima suya se metió en medio y los desapartó, y por esto el dicho Silvestre había dicho que juraba a Dios, porque se lo había estorbado, que había de hacer y acontecer.

También hubo de declarar en el proceso don Pedro de Portocarrero. A fin de cuentas, tras de toda esta causa, y tras de la de los capitanes revoltosos, no había otra intención que el limpiar la tierra de soldados con pretensiones, aun a costa de injusticia al 
no mirar los muchos méritos pasados, hechos en servicio del rey y a costa de sangre y hacienda.

Pasados los años, ya en el pueblecito cordobés de Las Posadas, la edad madura y la vejez de Silvestre no venian a resultar más que un largo y penoso epílogo de una mocedad guerrera y frustrada. Junto con los otros pedigüeños, el virrey marqués de Cañete lo había despachado del Perú a viva fuerza, rumbo a la Península, para que no importunase reclamando mercedes. Fracasada la expedición de Hernando de Soto, estériles sus trabajos en las guerras civiles peruanas, Silvestre se ve obligado a formar parte, ya en España, de la infinita legión de pretendientes que gastaban paciencia, tiempo y hasta dinero en obtener una recompensa de la corona, en atención a méritos propios o paternos. También figuró Garcilaso en esa legión, pidiendo mercedes reales en atención a su padre conquistador y su madre palla. Cuando ambos pedigüeños se encontraron en la Corte, joven el uno, hombre maduro el otro, tenían en común no sólo las pretensiones, sino la añoranza del Perú y de Indias; el ser mirados ambos como gente indiana, mal adaptada al mundo peninsular $y$, en fin, coincidían en el resentimiento por el mal pago, corto o ninguno, que recibieron de la corona. El encuentro debió alegrarlos a ambos y en particular al Inca, como solía ocurrirle siempre que topaba en España con algún perulero: en sus escritos deja complacida constancia de muchos de los que vio. $\omega$ A Silvestre lo encontró a poco de su llegadaj @ España.cinelli Converso"

Según los testimonios existentes, en opinión de Porras Barrenechea, Silvestre aparece como hombre colérico, violento e impetuoso; frente a él se halla Garcilaso, el joven mestizo recién llegado, fino, tímido, prudente, sensible. A pesar de esta disparidad de caracteres, ambos trabaron y reafirmaron una amistad para toda la vida. Sin duda, a Garcilaso debieron fascinarle los dotes narrativas de Silvestre, su aureola heroica de veterano, su fuerte personalidad. Era uno de esos viejos soldados que, descargando su memoria henchida, recitaban a porfía las hazañas propias y de sus compañeros, hasta convertirse en ejercitados artífices del relato verbal. Esa virtud natural de Silvestre, espontáneamente cultivada a lo largo de su vida, hería la sensibilidad creadora del Inca, una sensibilidad que creció con los recursos de la retórica y el saber humanístico. Tanto la belleza del asunto histórico, como el interés práctico de incitar a los españoles a la conquista de la 
Florida, despertaron en Garcilaso, desde muy temprano, la idea de componer una crónica de aquellos sucesos. "Importuné muchas veces a aquel caballero -escribe en el Proemio- que escribiésemos esta historia, sirviéndole yo de escribiente; y aunque de ambas partes se deseaba el efecto, lo estorbaban los tiempos y las ocasiones que se ofrecieron, ya de guerra, por acudir yo a ella, ya de largas ausencias que entre nosotros hubo, en que se gastaron más de veinte años". En aquel principio, ciertamente, Garcilaso no podía aspirar a más que a simple escribiente de Gonzalo Silvestre; pero llegado el momento de fabricar la historia, la situación recíproca de ambos había cambiado mucho, pues para entonces la formación humanística del Inca, su destreza literaria y sobre todo su conocimiento de la ciencia histórica de la época, le daban clara superioridad cultural sobre Silvestre. Pero el Inca, tanto por modestia, cuanto por la honda amistad que sentía por Silvestre, siempre hubo de presentarlo como el "autor" de la obra; o, para ser más exactos, como "mi autor".

Esos años de dilaciones en los cuales resultó imposible comFoner la obra, si bien fueron causa de que saliera a luz como una crónica tardía, trajeron en cambio apreciables ventajas, por permitir que Garcilaso, adiestrado durante la espera en el arte histórico, interrogase a su amigo con sagaz minuciosidad. Venciendo, pues, el amor al tema a la prolongada demora y a cuantas dificultades se presentarahblacobracpudo frealizarse al fin : "Empero -prosigue el Inca-J Greciéndomen con el tiempo el deseo, y por ctra parte el temor que si alguno de los dos faltaba, perecía nuestro intento, porque, muerto yo, no había él de tener quien le incitase y sirviese de escribiente, y, faltándome él, no sabía yo de quién pode[r] haber la relación que él podía darme, determiné atajar los estorbos y dilaciones que había con dejar el asiento y comodidad que tenía en un pueblo donde yo vivía y pasarme al suyo, donde atendimos con cuidado y diligencia a escribir todo lo qe en esta jornada sucedió". Ya vemos, pues, lo mucho que deseaba Garcilaso esta obra, hasta el extremo de que, temeroso de la mala salud de Silvestre, prefirió redactar la Florida antes que los Comentarios reales, es decir, antes que la historia misma de su patria.

Cuando, años después, muerto ya Silvestre, Garcilaso corregía su obra y recordaba al amigo, siempre lo menciona concediéndole un plano superior: "el que me daba la relación me lo 
mandó asi", escribe por ejemplo; un elegíaco afecto transparece en la humildad generosa de estas palabras, y "mi autor" lo llamará repetidas veces en diversos lugares de la obra.

Según demostramos, Gonzalo Silvestre alcanzó a concluir, en unión del Inca Garcilaso, la primera redacción de la Florida: fue, pues, verdadero coautor de ella, al menos en cuanto relación de los hechos narrados, o sea en cuanto crónica. Ya desde el punto de vista de la historia, con todo su artificio y profunda intención, la Florida no puede atribuirse sino a Garcilaso, sabio humanista y gran escritor. Pero siendo Silvestre, como consta, el coautor de la crónica, que no sólo proporcionó las noticias, sino que las revisó ya redactadas, es preciso establecer, de una vez por todas, que la Florida no es una versión de segunda mano, sino de testigo presencial. Por ello debe advertirse, categóricamente, que uno de los más grayes errores que suelen cometerse en la apreciación del valor historiográfico de la Florida, consiste en no estimarla como lo que en rigor es: una relación que, aunque tardía, es de primera mano. Acaso no suele considerarse la relación de Rodrigo Rangel como testimonio directo, no obstante que quien la redactó fué Gonzalo Fernández de Oviedo, hombre que ni remotamente se hallaba identificado con Rangel del modo como lo estaban el Inca y Silvestre?

Al tesonero empeño del Inca se debió, como vimos, la redacción de la florida. Insistió con el conquistador durante largos años, supo hacer llevadero sul carácter libronco, porfió hasta irse a vivir con él, abandonando su casa y pueblo, con tal de lograr su afón. Don fñigo de Córdova, quien los conoció, cuenta cómo llegó una vez a las posadas un tal Carriilo, "que era un truhán, a burlarse con Gonzalo Silvestre, y puso mano a la espada para matarle, yo me acuerdo, cuando Garcilaso de la Vega escribía estos libros". ¡Así era de altivo y colérico este viejo soldado, cuando su edad iba por los setenta y andaba él "tullido de bubas y de heridas"! El mismo testigo lo recuerda como "hombre viejo y grande de cuerpo, y hombre de mala condición". Pero el don de gentes y la prudencia de Garcilaso vencieron el mal carácter de Silvestre, así como habían vencido las dificultades de la larga espera. Y no acabó todo allí, sino que, poniendo en juego no sólo su voluntad, sino su inteligencia y sabiduría, Garcilaso interrogó metódicamente al conquistador sobre los sucesos de la jornada. Gracias a tanta paciencia, la versión de Silvestre, escrita 
casi medio siglo después de los acontecimientos, resulta muchísimo más rica en pormenores, más vívida en la recontsrucción de ambientes y escenarios, que las crónicas antiguas de Biedma, Rangel $\circ$ el Hidalgo de Helvas. El propio Inca, no obstante su decisión de ceder la paternidad de la historia a su innominado amigo, subraya en el Proemio que no le ayudaban poco a Silvestre, "para volver a la memoria los sucesos pasados, las muchas preguntas y repreguntas que yo, sobre ellos y sobre las particularidades y calidades de aquella tierra, le hacía".

Ya tenemos aquí al historiador en pleno ejercicio. Garcilaso sabía muy bien que la exactitud de las informaciones dependía de Silvestre, y tuvo la cautela de someterle la corrección de cuanto llevaba escrito. Así iba reviviéndose el mundo de la jornada, en un proceso que se iniciaba con el sagaz aprovechamiento de la memoria del conquistador; continuaba al poner luego en juego el Inca toda su fantasía re-creadora, al exponer esas noticias en rica prosa; y el ciclo se cerraba al certificarse esos originales mediante la aprobación del informante y testigo. Refiriendo dicho proceso, dice el Inca que Silvestre quiso ser tan fiel en su relación que, capítulo por capítulo, los iba corrigiendo, quitando o añadiendo lo que faltaba o sobraba de lo que él había dicho, que ni una palabra ajena por otra de las suyas nunca las consintió; de manera que yo no puse más de la pluma, como escribiente". Puso más, en rigor : todo su saber histórico al interrogar a su "autor", al ordenar las noticias y disponerlas con avisada intención. De єsta manera, dejandó volar la plumal el escritor-poeta, y sometiendo el texto a la verdad histórica, fue lográndose el fruto final. Siempre consciente de su papel de historiador, comprensivo de que el valor testimonial era de Silvestre y no suyo, y ducho, en fin, en el trato con su amigo, el Inca sometía su propia opinión a la del testigo, con sabia docilidad. "Y porque éste -el templo de Cofachique, escribe- fue el más rico y soberbio de todos los que nuestros españoles vieron en la Florida, me pareció escribir tan larga y particularmente las cosas que en él había, y también porque el que me daba la relación me lo mandó así, por ser una de las cosas, como él decía, de mayor grandeza y admiración de cuantas había visto en el Nuevo Mundo, con haber andado lo más y mejor de México y del Perú". 'Cuánta prudencia, sabiduría y amistad hay detrás de estas hermosas y humildes palabras!

Casi medio siglo después de la expedición, el esfuerzo de ambos amigos por recordar y reconstruir ordenadamente lo ocu- 
rrido, abundando en anécdotas y pormenores, consignando nombre por nombre a muchos soldados de aquella jornada, aparece como algo de todo punto admirable. Así pudo afirmar Garcilaso, con entera justicia, que "aun ha sido mucho haber sacado en limpio esto poco, al cabo de tantos años". Y ese "poco" fué nada menos que la relación más amplia y minuciosa de cuantas han llegado a nuestros días. Por otra parte, resulta dudoso que Silvestre conservara muchos apuntes tornados durante la jornada: $\in n$ todo caso no los alegó en su información de servicios hecha anto el Consejo de Indias, en Valladolid, en 1558, por lo cual puede muy bien negarse que existieran. Tampoco parece haber usado una copia de esa información al componer la Florida. Además, hubo etapas de la expedición de las que Silvestre guardó poca memoria, como cuando confiesa ignorar los nombres de ciertas provinciás y lo explica diciendo que los restos de la expedición, a órdenes de Luis de Moscoso de Alvarado, "como ya no tenían intención de poblar, no procuraban saber los nombres, ni informarse de las calidades de las tierras; sólo pretendían pasar por ellas con toda la priesa que podíam, y por esto no tomaron los rombres, ni pudieron dármelos a mí". De otro lado, contra la lucidez de los recuerdos de Silvestre debió atentar la fatiga de su ancianidad, y la que sin duda le causaban sus males, los cuales a poco lo llevaron a la tumba. Sobre tantos inconvenientes, el fruto obtenido por ambos amigos causa verdadero pasmo; pero no paraba todorallí. Puccinelli Converso»

En su celo por ofrecer noticias ciertas, Garcilaso, según vimos, envió parte de la Florida al doctor Ambrosio de Morales, para que cotejase la versión de Silvestre con documentos que el doctor poseía; como el resultado fué satisfactorio, Garcilaso tuvo así la seguridad de que la memoria del conquistador merecía confianza. Por otra parte, se advierte que el Inca interrogó a cuantas gentes pudo acerca de la Florida. En algún pasaje habla de que, "aunque lo procuré saber, no me fue posible, por lo cual se me perdonará esta falta"; luego, en otro lugar, repetirá idénticas palabras: "aunque lo procuré saber"; en ambos casos parece referirse no sólo a Silvestre, sino a otros testigos. También cuenta, en otra ocasión, haber "oído a personas fidedignas que ha acaecido hallar los indios de la costa de la Florida talegos de plata de navíos que, con la tormenta, han dado al través en ella, y llevarse el talego, como cosa que había de ser de más provecho, y de- 
jar la plata, por no la preciar ni saber qué fuese". Y así también, como vimos anteriormente, al ponderar el heroísmo de los indios de la laguna de Vitachuco, subraya: "Hañaza por cierto increíble, y que yo no osara escribirla si la autoridad de tantos caballeros y hombres grandes que, en Indias y en España, hablando de ella y de otras que en este descubrimiento vieron, no me la certificaran, sin la autoridad y verdad del que me dio la relación". Al parecer, ya desde el Perú conocía Garcilaso algunos episodios de la expedición de Soto a la Florida, y en España volvió a hablar de ello con diversas gentes, bien testigos directos, bien - al menos algunos- indirectos.

Gracias, pues, a una singular amistad, nació y creció este libro admirable, no menos importante, porque algunas pequeñas inexactitudes parezcan disminuirlo. Esa vida heroica, pero frustrada, de Gonzalo Silvestre, tan llena de glorias pasadas como pobre en realidades presentes, se hubiera consumido infecunda, definitivamente estéril, a no ser por la Florida. La fe de Garcilaso, esa porfía rebosante de noble pasión, acabó por vencer el extraño desgano que tuvo Silvestre por reunir sus memorias; el propio Inca habla del temor de que, si faltara él, ningún otro "incitaría" a Silvestre a esos trabajos. Pero como todo aquello que se desea y espera largamente, el libro llegó al fin y en él Gonzalo Silvestre, callado como "autor" o informante, aparece de continuo como típico guerrero lleno de ărrojót de esa impaciente cólera española que, según testimonios, conservó hasta el fin de sus días. 